\title{
A report on features of three- and four-part proximal humeral fractures and outcome of internal fixation using the philos $®$ locking plate
}

\begin{abstract}
Background: Proximal humeral fractures are among prevalent types of fractures and remain a challenging issue for surgical management. This study aimed to assess the clinical outcomes and complication rates of three- vs. four-part proximal humeral fractures, treated with internal fixation using the Philos ${ }^{\circledR}$ plate.
\end{abstract}

Material and Methods: In this cohort study, a total of 30 consecutive patients with three-part or four-part proximal humeral fractures based on the Neer classification were included. Surgical treatment was performed with open reduction and internal fixation using the Philos ${ }^{\circledR}$ plate. Constant score was evaluated 6months later in follow-up. P-value $<0.05$ was considered significant.

Results: Four-part fractures were mainly caused by a trauma from above, while insults of opposite direction were responsible for more than half of 3 part fractures $(\mathrm{P}$-value $=0.010)$. Open fractures were only observed in patients with four-part fracture $(P$-value $=0.018)$. No significant differences were noticed regarding gender, cause and side of fracture. Presence of other fractures, fracture of implant, reduction loss, avascular necrosis (AVN) of humerus head, rotator cuff injury, and revision surgery were significantly higher in patients with four-part fractures. Constant score was $81.40 \pm 11.61$ and $65.09 \pm 16.09$ for three-part and four-part fractures, respectively (P-value $=0.006)$.

Conclusion: Open reduction and internal fixation with Philos ${ }^{\circledR}$ plate yields acceptable results in both types of fractures, however prognosis of this intervention is poorer four-part fractures.

Keywords: internal fixators, bone plates, proximal humeral fractures
Volume 4 Issue 2 - 2017

\author{
Ali Sadighi,' Alireza Sadeghpour,' Hossein \\ Aslani,' Hojjat Hossein Pourfeiz,' Bahamin \\ Attar,' Zahra Azizian² \\ 'Orthopaedic Surgery, Tabriz University of medical sciences, Iran \\ ${ }^{2}$ Dermatology resident, Iran University of medical sciences, Iran
}

\begin{abstract}
Correspondence: Zahra Azizian, Orthopaedic Surgery, Shohada Hospital, Tabriz University of medical sciences, Iran, Email Azizian_z@yahoo.com
\end{abstract}

Received: February 06, 2017 | Published: April 05, 2017

\section{Introduction}

Proximal humeral fractures account for circa $4 \%$ of all types of fractures and $26 \%$ of fractures of humerus. ${ }^{1}$ Approximately $13-16 \%$ of proximal fractures are multi-fragmented three- and four-part ones. ${ }^{2}$ Proximal humerus fractures are largely considered to be osteoporosisassociated particularly affecting the active elderly as a result of minimal trauma. ${ }^{3}$ As a result, these fractures have a substantial negative impact on the quality of life and independence of patients, as well as financial burden on health care systems. ${ }^{4}$ Various surgical techniques have been proposed for fixation of comminuted and displaced proximal humeral fractures with the aim of proper restoration of a painless shoulder fulfilling patient's functional demands. However, these procedures pose difficult management problems and are not free of adverse events. Potential complications include avascular necrosis (AVN) of the humeral head, displaced tuberosity fragments, malunion or non-union, rotator cuff impingement, implant failure, painful frozen shoulder, neurovascular problems and arthritis. ${ }^{5,6}$ Complexity of the fracture, severity of soft tissue injury, patient's age, male sex, preexisting comorbidities and bone density have been reported as influential factors for failure and complication after surgery.,

Locking compression plates have been recently utilized in proximal humeral fracture fixation and gained great popularity. The Proximal Humeral Internal Locking System (Philos $\left.{ }^{\circledR}\right)$ plate has specifically been designed to provide stability in proximal humeral fractures. It can be applied with a minimally invasive method and has screws which are placed in converging and diverging directions. ${ }^{9}$ Several holes in the proximal part of the plate function as suturing anchors to the rotator cuff. Early postoperative mobilization and lower rate of complications are advantages of this device. ${ }^{10}$ The purpose of this prospective study was to present a comparison of the clinical outcomes and complication rates of 30 patients with three- vs. four-part proximal humeral fractures, who were treated with internal fixation using the Philos ${ }^{\circledR}$ plate in our center.

\section{Material and methods}

In this cohort study, 30 patients with three part or four part proximal humeral fractures based on the Near classification ${ }^{11}$ were included. The patients were treated in Shohada Hospital, from September 2012 to June 2014. Inclusion criteria also consisted of age between 18 to 80 years and referral within the first 10 days after fracture. Patients with history of metastatic tumors were excluded. The study was approved by Ethics Committee of Tabriz University of Medical Sciences and an informed written consent was obtained from each patient prior to participation. Surgical treatment was performed with open reduction and internal fixation with the Philos ${ }^{\circledR}$ plate. Degree of bone healing, range of motion in shoulder, necrosis of humerus head, and nerve damage were evaluated 6months later in follow-up using the Constant 
score. ${ }^{12}$ Statistical analysis was conducted with IBM SPSS Statistics Software using Wilcoxon signed-rank test and the independent t-test. A P-value $<0.05$ was considered significant.

\section{Results}

A total of 30 consecutive patients with proximal humeral fractures were treated with the Philos ${ }^{\circledR}$ plate between 2012 and 2014 in our center. Average age of participants was $43.4 \pm 14$.45years (Mean \pm SD). Women comprised $40 \%(\mathrm{~N}=12)$ of all patients with the average age of $45.58 \pm 16.05$ years, and men made up the remaining $60 \%(\mathrm{~N}=18)$ with the average age of $41.94 \pm 13.58$ years. Demographic characteristics of three-part and four-part fractures regarding gender, side, cause, direction of traumatizing energy, and closed vs. open type are shown in table 1.4 part fractures were mainly caused by a source of energy in downward direction injuring the shoulder from above, while insults of opposite direction were responsible for more than half of 3 part fractures. This led to a significant difference with $\mathrm{P}$-value $=0.010$. Furthermore, none of 3 part fractures resulted in open wounds, while 3 out of 11 patients with 4 part fracture were afflicted by open fractures. This difference was also significant with a P-value of 0.018 . However, in terms of gender, cause and side of fracture no significant differences were noticed.

Additionally, accompanying complications were assessed and the results are listed in Table 2. Presence of other fractures, fracture of implant, reduction loss, avascular necrosis (AVN) of humerus head, rotator cuff injury, along with necessity of performing revision surgery were significantly higher in patients with 4 part fractures. This is of note that in all cases with loss of reduction, implant fracture was also present. Nonunion was not observed in any of the patients.

Table I Features of 3 part and 4 part fractures

\begin{tabular}{|c|c|c|c|c|c|}
\hline & \multirow{2}{*}{ Features } & \multirow{2}{*}{$\begin{array}{c}\text { Total } \\
\mathbf{N}=\mathbf{3 0}\end{array}$} & \multirow{2}{*}{$\begin{array}{l}3 \text { Part } \\
\mathrm{N}=19\end{array}$} & \multirow{2}{*}{$\begin{array}{l}4 \text { Part } \\
\mathrm{N}=1 \mathrm{I}\end{array}$} & \multirow{2}{*}{0.2} \\
\hline & & & & & \\
\hline \multirow{2}{*}{1} & Male & $18(60 \%)$ & II (36.7\%) & 7 (23.3\%) & \\
\hline & Female & $12(40 \%)$ & $8(26.7 \%)$ & 4 (13.3\%) & \\
\hline \multirow{2}{*}{2} & Right & 8 (26.7\%) & 4 (13.3\%) & 4 (13.3\%) & 0.369 \\
\hline & Left & 22 (73.3\%) & 15 (50\%) & 7 (23.3\%) & \\
\hline \multirow{2}{*}{3} & Accident & I4 (46.7\%) & $8(26.7 \%)$ & $6(20 \%)$ & 0.512 \\
\hline & Falling down & $16(53.3 \%)$ & II (36.7\%) & 5 (16.6\%) & \\
\hline \multirow{2}{*}{4} & From above & $18(60 \%)$ & $8(26.7 \%)$ & $10(33.3 \%)$ & 0.01 \\
\hline & From below & 12 (40\%) & II (36.7\%) & I (3.3\%) & \\
\hline \multirow{2}{*}{5} & Closed & 27 (90\%) & 19 (63.3\%) & $8(26.7 \%)$ & 0.018 \\
\hline & Open & $3(10 \%)$ & 0 & $3(10 \%)$ & \\
\hline
\end{tabular}

Table 2 Complications associated with the primary thee-part and four-part proximal humeral fractures

\begin{tabular}{llllll}
\hline \multirow{2}{*}{ Complication } & Total & $\mathbf{3}$ Part & $\mathbf{4}$ Part & \multirow{2}{*}{ P-Value } \\
\cline { 2 - 4 } & $\mathbf{N = 3 0}$ & $\mathbf{N = 1 9}$ & $\mathbf{N}=$ I I & \\
\hline I & Presence of other fractures & $9(30 \%)$ & $3(15.8 \%)$ & $6(54.5 \%)$ & 0.028 \\
2 & Articular surface involvement & $9(30 \%)$ & $5(26.3 \%)$ & $4(36.4 \%)$ & 0.569 \\
3 & Nerve damage & $4(13.3 \%)$ & $2(10.5 \%)$ & $2(18.2 \%)$ & 0.559 \\
4 & Implant failure & $3(10 \%)$ & I (5.3\%) & $2(18.2 \%)$ & 0.018 \\
5 & Reduction loss & $3(10 \%)$ & 0 & $3(27.3 \%)$ & 0.018 \\
6 & Varus malunion & $7(23.3 \%)$ & $3(15.8 \%)$ & $4(36.4 \%)$ & 0.207 \\
7 & AVN of humerus head & $5(16.7 \%)$ & I (5.3\%) & $4(36.4 \%)$ & 0.03 \\
8 & Replacement & $7(23.3 \%)$ & $4(21.1 \%)$ & $3(27.3 \%)$ & 0.703 \\
9 & Rotator cuff injury & $7(23.3 \%)$ & $2(10.5 \%)$ & $5(45.5 \%)$ & 0.032 \\
10 & Impingement syndrome & $6(20 \%)$ & $3(15.8 \%)$ & $3(27.3 \%)$ & 0.456 \\
II & Revision surgery & $3(10 \%)$ & 0 & $3(27.3 \%)$ & 0.018 \\
I2 & Infection & I (3.3\%) & 0 & I (9.1\%) & 0.189 \\
\hline
\end{tabular}

*Percentages are related to the item in top of columns.

$* * \mathrm{AVN}=$ Avascular necrosis. 
The total average Constant score was $75.63 \pm 15.47$ (Women: $72.67 \pm 9.27$, Men: $77.61 \pm 18.51)$. This score was $81.40 \pm 11.61$ and $65.09 \pm 16.09$ for 3 part and 4 part fractures respectively, which showed a statistically significant difference $(\mathrm{P}-\mathrm{value}=0.006)$.

\section{Discussion}

Locking plates are a new method with promising results; nonetheless unsatisfactory outcomes have been reported. In a systematic review of locking plate fixation of proximal humerus fractures by Sproul et al., ${ }^{6}$ which investigated 12 studies including 514 patients the rate of complications were reported as follows: $16 \%$ varus malunion, $10 \% \mathrm{AVN}, 6 \%$ impingement, and $4 \%$ infection. $14 \%$ needed reoperation. Gaheer et al., ${ }^{13}$ studied 56 patients with threeor four-parts fractures, who underwent internal fixation surgery using Philos ${ }^{\circledR}$ plate. In one case, screw disengagement from to plate led to revision surgery. Stiffness was observed in 3 patients, which improved with intensive physiotherapy. Similar to our study, only one patient developed superficial wound infection, who responded to oral antibiotic therapy. Another comparable study was conducted by Norouzi et al., ${ }^{14}$ in a teaching hospital in Tehran on 37 patients with 2-, 3- and 4-part fractures. The results were in favor of application of the Philos plate, as this method offered great outcomes with low risk of complication; AVN and infection were notice in only one and two cases, respectively.

Eighty-two cases were evaluated by Erasmo et al., ${ }^{15}$ in Italy. Twelve patients required revision surgery, 10 presented with AVN These findings were higher compared to our study. Furthermore, nonunion was noted in 3 patients, which was non-existent in our study.

In a similar study by Shadid et al., ${ }^{2}$ form England, it was shown that younger age and male gender were factors with positive effect on the outcome of surgery. Also, the authors claimed that number of fragments apparently do not affect the results, which was contrary to our study. In a long-term follow up of 64 patients by Hirschmann ${ }^{16}$ in Switzerland, the overall outcomes were favorable especially in younger patients and patients undergoing revision surgery, who had a rate of $29 \%$. Older age and requiring revision surgery were mentioned as the most predictive factors yielding undesirable outcome. Two other reports from early experiences by Moonot \& Koukakis ${ }^{9,10}$ have also provided valuable information with almost similar outcomes. In the study by Moonot, it was mentioned that good bone density permits early post-operative mobilization of upper extremity. To the best of our knowledge, there is no study on comparison of 3- and 4-part fractures of proximal humerus. Based on our results, it can be concluded, that the risk benefit may not be justifiable for 4-part fractures. However further studies are necessary to investigate this aspect.

\section{Limitations and suggestions}

One of the shortcomings of our study is that the number of participants was limited and patients in the three- and four-part fracture groups were not matched with regards to their gender, age, and predisposing factors. This fact may have led to bias in the presented results. In addition, comparison of the outcomes in internal fixation with Philos ${ }^{\circledR}$ plate method to other conservative and operative managements can shed light on the differences in terms of potential complications in three- vs. four-part proximal humeral fractures and be valuable for clinical decision making.

\section{Acknowledgements}

None.

\section{Conflict of interest}

The author declares no conflict of interest.

\section{References}

1. Court-Brown CM, Garg A, McQueen MM. The epidemiology of proximal humeral fractures. Acta Orthop Scand. 2001;72(4):365-371.

2. Shahid R, Mushtaq A, Northover J, et al. Outcome of proximal humerus fractures treated by PHILOS plate internal fixation. Experience of a district general hospital. Acta Orthop Belg. 2008;74(5):602-608.

3. Court-Brown CM, Caesar B. Epidemiology of adult fractures: a review. Injury. 2006;37(8):691-697.

4. Slobogean GP, Johal H, Lefaivre KA, et al. A scoping review of the proximal humerus fracture literature. BMC Musculoskelet Disord. $2015 ; 16(1): 112$.

5. Nouraei MH, Majd DA, Zamani F. Comparing the treatment results of proximal humerus fracture based on surgical or nonsurgical methods. Adv Biomed Res. 2014;3:253.

6. Sproul RC, Iyengar JJ, Devcic Z, et al. A systematic review of locking plate fixation of proximal humerus fractures. Injury. 2011;42(4):408413.

7. Krappinger D, Bizzotto N, Riedmann S, et al. Predicting failure after surgical fixation of proximal humerus fractures. Injury. 2011;42(11):1283-1288.

8. Petrigliano FA, Bezrukov N, Gamradt SC, et al. Factors predicting complication and reoperation rates following surgical fixation of proximal humeral fractures. J Bone Joint Surg Am. 2014;96(18):1544-1551.

9. Moonot P, Ashwood N, Hamlet M. Early results for treatment of threeand four-part fractures of the proximal humerus using the PHILOS plate system. J Bone Joint Surg Br. 2007;89(9):1206-1209.

10. Koukakis A, Apostolou CD, Taneja T, et al. Fixation of proximal humerus fractures using the PHILOS plate: early experience. Clin Orthop Relat Res. 2006;442:115-120.

11. Neer CS. Displaced proximal humeral fractures. J Bone Joint Surg Am. 1970;52(6):1077-1089

12. Constant CR, Gerber C, Emery RJ, et al. A review of the Constant score: modifications and guidelines for its use. J Shoulder Elbow Surg. 2008;17(2):355-361.

13. Gaheer RS, Hawkins A. Fixation of 3-and 4-part proximal humerus fractures using the PHILOS plate: mid-term results. Orthopedics. 2010;33(9):671.

14. Norouzi M, Naderi MN, Komasi MH, et al. Clinical results of using the proximal humeral internal locking system plate for internal fixation of displaced proximal humeral fractures. Am J Orthop (Belle Mead NJ). 2012;41(5):E64-E68.

15. Erasmo R, Guerra G, Guerra L. Fractures and fracture-dislocations of the proximal humerus: A retrospective analysis of 82 cases treated with the Philos ${ }^{\circledR}$ locking plate. Injury. 2014;45:S43-S48.

16. Hirschmann MT, Fallegger B, Amsler F, et al. Clinical longer-term results after internal fixation of proximal humerus fractures with a locking compression plate (PHILOS). J Orthop Trauma. 2011;25(5):286-293. 